\title{
ESTUDOS ORGANIZACIONAIS: POSSÍVEL QUADRO REFERENCIAL E INTERFACES
}

\section{Michel Thiollent ${ }^{1}$}

\section{Resumo}

Este artigo tem como objetivo esboçar de forma resumida uma visão dos Estudos Organizacionais, praticável em nossas atuais condições de trabalho universitário no Brasil, sem depender muito de padrões já existentes. Apresenta um conjunto de reflexões provisórias, com alusões a determinados autores ou escolas de pensamento que os estudiosos da área reconhecerão com facilidade.

Palavras-chave: Estudos Organizacionais; Tendências; Métodos.

\section{ORGANIZATIONAL STUDIES: POSSIBLE REFERENCE FRAMEWORK AND INTERFACE}

\begin{abstract}
This article aims to sketch briefly a vision of organizational studies, feasible in our current college working conditions in Brazil without much depend on already existing standards. It presents a reflections set provisional, with allusions to certain authors or thought schools which os scholars will recognize easily.
\end{abstract}

Keywords: Organization Studies; Trends; Methods.

${ }_{1}^{1}$ Professor Adjunto do PPGA-UNIGRANRIO. E-mail: m.thiollent@gmail.com

Revista Brasileira de Estudos Organizacionais • v. 1. n. 1, p. 17-29, jun. 2014, eISSN: 2447-4851

Sociedade Brasileira de Estudos Organizacionais 


\section{Introdução}

O objetivo é aqui esboçar de forma resumida uma visão dos Estudos Organizacionais, praticável em nossas atuais condições de trabalho universitário no Brasil, sem depender muito de padrões já existentes. Precisamos evitar o mimetismo que é comum nos estudos convencionais e, por vezes, continuado na busca de alternativas.

Trata-se de apresentar um conjunto de reflexões provisórias, com alusões a determinados autores ou escolas de pensamento que os estudiosos da área reconhecerão com facilidade. Nosso trabalho consiste em pensamentos, opiniões, modos de ver, sugestões que resultam de um percurso de algumas décadas de trabalho universitário, sempre procurando mais liberdade e senso crítico, porém sem dogmatismo.

Assim, nesta comunicação, tentaremos definir o escopo dos Estudos Organizacionais e esboçar um quadro referencial enfatizando o potencial crítico. Sem preocupação com delimitações paradigmáticas, mostraremos o espaço aberto por esses Estudos sobre temas e questões da realidade organizacional com diversas interfaces sociais, psicológicas, políticas, as quais podendo ser abordadas com interdisciplinaridade ou trandisciplinaridade. Também será discutido o uso de vários métodos de tipo qualitativo. À guisa de conclusão, serão evocados os compromissos intelectuais vinculados ao desenvolvimento dos Estudos Organizacionais.

\section{Escopo dos Estudos Organizacionais}

Os Estudos Organizacionais constituem uma área de pesquisa sobre organizações, suas características culturais, econômicas, políticas e sociais e seus efeitos sobre os indivíduos e grupos que as compõem ou com que interagem. Tal área requer conhecimentos oriundos de várias disciplinas, ciências sociais e humanas teóricas e aplicadas, interfaces com filosofia, epistemologia, psicologia, ética, tecnologia, biologia, ecologia e outras, a serem articuladas de diferentes modos (inter ou transdisciplinar) e com diversas ênfases temáticas.

O conceito de organização - que não se deve fetichizar - é aplicado para designar empresas, como também instituições ou entidades públicas, políticas ou sociais, e pode ser estendido a outros tipos de vida social organizada. São estudadas as práticas organizativas como conjuntos de ações, aplicações de princípios, exercício de poder e demais aspectos como controle, regulação, descriminações, identidade e diferenciação cultural, evolução, inovações, transformações e até destruição.

Os Estudos Organizacionais podem ser conduzidos em perspectiva crítica, isto quer dizer, estudos em que não se adota a priori a normatividade inerente às vigentes relações de poder, nem se conforma aos interesses dos detentores do capital e de seus intermediários. Isto é 
diferente da maioria das concepções prevalentes em Administração de Empresas ou de Negócios, porque não se restringe ao lado prescritivo da gestão corrente que permanece norteada pela busca de lucratividade ou a razão custo/benefício. Ao contrário, analisam-se as situações, interações ou outras características relacionadas com estruturas, processos, efeitos das organizações, com base nas perspectivas recíprocas dos múltiplos atores envolvidos, inclusive as dos grupos subordinados ao poder e até as dos outsiders, contestadores ou dissidentes.

O foco de interesse principal não está nas performances (ou desempenho) de entidades, grupos ou indivíduos, mas no significado dos fatos e comportamentos que acontecem no âmbito das práticas organizativas.

As organizações agem e evoluem em função de fatores de competição, posições de mercado, estratégias de atividades, interações em redes. Todavia, sem se negar a importância desses fatos, podemos acrescentar aspectos de cooperação e cooperatividade, lutas por posicionamentos ideológicos, desdobramentos simbólicos e "efervescentes" imprevisíveis na concepção instrumental das organizações. É também desejável prestar atenção às condições de trabalho, condições de vida e saúde humana, associadas aos modelos e práticas organizacionais. É conhecido o fato de que, com a extrema competitividade, entre organizações ou internamente, acentua-se a precarização do emprego, intensificam-se os ritmos de trabalho, aumentam vários fatores: carga mental exigida, estresse, depressão, riscos de acidentes em todos os setores de atividade (serviços, indústria, agropecuária). Esses aspectos podem ser descritos e analisados por disciplinas isoladas (ergonomia, psicologia do trabalho, psicopatologia, etc.), como também interpretadas de modo mais abrangente em Estudos Organizacionais.

\section{Esboçando um quadro referencial para Estudos Organizacionais}

Existem diversas concepções de Estudos Organizacionais nos mundos anglo-saxônico, escandinavo, francofônico, latino-americano.

Os referenciais de Estudos Organizacionais, em perspectiva crítica, são influenciados por autores de diferentes escolas de pensamento: marxismo, anarquismo, pensamento nietzschiano, psicanálise, gramscismo, pensamento da Escola de Frankfurt (incluindo autores fundadores e atuais continuadores), fenomenologia, hermenêutica, existencialismo, pensamento pós-moderno, pensamento de intelectuais franceses críticos (filósofos, sociólogos, psicólogos, historiadores), pensamento crítico brasileiro e latino-americano, inclusive teologia da libertação. 
Em muitos lugares do Norte tende a prevalecer o CMS - Critical Management Studies - em que se desenvolvem críticas e visão alternativa ao tradicional Management cujos pressupostos são geralmente neoliberais e positivistas.

Sem dúvida, é de fundamental importância levar em conta as diversas tendências internacionais e, em particular, a contribuição crítica do CMS, porém isso não nos dispensa de pensar como docentes ou pesquisadores do Sul, onde, de longa data, existem diversas tendências e nuanças de pensamento crítico, expressadas por autores como Maurício Tragtenberg, Alberto Guerreiro Ramos, Paulo Freire, Álvaro Vieira Pinto e alguns outros. A releitura desses autores é importante para redesenhar os referenciais de Estudos Organizacionais em perspectivas críticas enraizadas na cultura do Sul.

Essas tendências constituem um pano de fundo com o qual o estudioso pode fazer seleções ou opções para desencadear suas múltiplas reflexões, observações, interpretações de fatos situacionais. Não são consideradas como paradigmas e elas não existem de modo sucessivo, uma apagando a anterior. São heterogêneas, há conflitos de interpretação, oposições, contradições, por vezes complementaridade e consenso. Importa aos pesquisadores conhecerem as características de cada tendência para evitar confusões ou agregações artificiosas.

As múltiplas influências recebidas na área de Estudos Organizacionais convergem, divergem ou se sobrepõem, criando espaços conceituais e metodológicos qualitativos e diferenciados, devido às ênfases dadas a diferentes tendências. Isso nos leva a abandonar o uso da classificação em paradigmas, blocos de conhecimentos supostamente coesos que entram em luta com os padrões anteriores para estabelecer nova ortodoxia. Tanto a visão de paradigmas fechados como a visão fragmentada, ou mais flexível das abordagens multiparadigmáticas, parecem inadequadas diante da complexidade e multiplicidade das abordagens possíveis ou existentes em dada época nas ciências humanas e sociais em geral e nos Estudos Organizacionais em particular. Independentemente de Thomas Kuhn, para certos pesquisadores, paradigma se tornou uma preocupação de rotulação ou de classificação que simplifica demais as conjunturas intelectuais, sempre mutáveis e inconclusivas, por vezes, confusas e ambíguas. Para além da questão da unicidade ou da multiplicidade de paradigmas (conjuntos ou subconjuntos de regras estabelecidas e reconhecidas), os quadros referenciais operando nos Estudos Organizacionais, aqui sugeridos, se abrem à intertextualidade ou à interdiscursividade de diferentes atores sociais e ao debate entre interlocutores de visões e posições diferenciadas. A imposição de regras fixas limita a possibilidade de interlocução e interessa principalmente aos grupos que querem exercer o poder ou se manter no poder. Em visão alternativa, as regras são mutáveis, passíveis de várias interpretações, formam um conjunto sempre incompleto e suas aplicações podem variar 
no tempo e no espaço. Além do lado explícito, há zonas de potencialidade, virtualidade, latência.

A cultura do capitalismo e a visão de mundo que lhe é associada em todos os níveis estão maciçamente propagadas pelas escolas, universidades, meios de comunicação e mundo empresarial em geral. Está presente nos discursos gerenciais, nos noticiários econômicos, na propaganda comercial, nos conteúdos do ensino em Administração em seus vários níveis. Parece existir um continuum entre o discurso corporativo de comentaristas de rádio-TV e o de seletos doutores em management. Diante desse cerceamento conformista, o pensamento crítico tende a ocupar um espaço bem reduzido. A grande maioria dos alunos de graduação em Administração, e de outras áreas, nunca estudou ou nem sequer ouviu falar de autores críticos. Esses autores aparecem como referências em certos cursos de pós-graduação ou em projetos de pesquisa, mas mesmo assim, de forma minoritária.

Seja qual for a importância histórica que tiveram, as concepções organizacionais desenvolvidas no passado dificilmente ultrapassam seu tempo e, portanto, não dão conta de situações ou problemas atuais. É preciso um esforço de contextualização e interpretação para se evitarem no presente simples aplicações ou transposições. Existem usos inadequados ou dogmáticos de concepções históricas de séculos passados que se revelam prejudiciais à observação das realidades hodiernas e à construção de novas explicações e/ou interpretações. Ademais, os saltos da história transformam os significados. Para simplificar, digamos que o Iluminismo europeu era progressista no século XVIII, na luta contra o feudalismo e as monarquias, e seus desdobramentos favoráveis ao capitalismo se tornaram reacionários e colonizadores a partir do século XIX. Por sua vez, o marxismo era revolucionário ou emancipatório no século XIX e tornou-se, em sua vertente "ortodoxa", conservador e autoritário no século XX. Cada doutrina segue um ciclo de vida. Em cada época, o conhecimento do futuro precisa ser "inventado" ou construído, com base nos escombros dos períodos anteriores. A história pode tratar de resgatar a memória social e, em especial, a de movimentos de ideias ou de formas de organização que foram esquecidas e que podem ser objeto de ressignificação.

No mundo das organizações podemos constatar ao longo do tempo oscilações entre o espírito de participação e o espírito autoritário. Existem ciclos de autoritarismo, eventualmente seguidos por ciclos de busca de democratização, participação, humanização. Nos anos 60, em países escandinavos, a chamada "Democracia Industrial" com sistema de negociação tripartite contribuiu para valorizar a participação dos trabalhadores e dos sindicatos em algumas empresas e serviu de modelo de inspiração em concepções gerenciais propagadas em diversos países. Posteriormente, o modelo asiático com processos gerenciais mais autoritários, sem reconhecimento da capacidade de ação ou da 
possibilidade de autonomia dos trabalhadores, acabou prevalecendo tanto nas práticas quanto no ideário gerencial.

Novas formas de autoritarismo se manifestam nas empresas com a radicalização do sistema de controle e vigilância, a banalização do assédio moral e outros constrangimentos. Em ampla parte do mundo, isso se constata, em particular, na conexão do ideário gerencialista do neoliberalismo de origem ocidental com as práticas gerenciais de origem asiática, de geração mais recente que o modelo japonês dos anos 1980, levando a uma extrema pressão sobre os trabalhadores.

O questionamento do autoritarismo nas organizações pode ser considerado como um dos eixos principais, da abordagem crítica em Estudos Organizacionais. Vale destacar o estudo da evolução das formas de autoridade e de autoritarismo nas organizações. $O$ autoritarismo já era analisado por Maurício Tragtenberg nos anos 1960/80, a crítica tem sido continuada por Faria (2007). Foram também destacados outros aspectos: Dejours (2000) fala em banalização do sofrimento no trabalho e da cega aplicação de ordens vindas de cima, como no nazismo. Por sua vez, Boaventura de Sousa Santos (2004, p. 45-48) evoca o "fascismo social" nas relações empresariais sob o domínio neoliberal, submetendo milhões de pessoas aos interesses de grupos elitizados por meio de privatizações, terceirização e outros tipos de regulação.

Outro eixo importante é a reafirmação da centralidade do trabalho como objeto de estudo. Contrária à visão gerencialista que minimiza a importância do trabalho humano e atribui à gerência a inteira valorização da produção e todos os poderes decorrentes, a visão crítica põe em evidência a coisificação à qual são submetidos os seres humanos como meros apêndices dos equipamentos e máquinas.

De acordo com uma visão crítica dos Estudos Organizacionais, podemos apontar alguns temas a serem aprofundados:

- Crítica das práticas, pressupostos e "fundamentos" do conhecimento administrativo. Isto requer que se tome um recuo com relação aos discursos dominantes e que se mobilizem todos os recursos teóricos, conceituais e metodológicos possíveis, não limitados a uma única escola de pensamento;

- Crítica dos conteúdos, estilos, condições de uso, publicação e difusão de conhecimento em administração e gestão;

- Crítica dos efeitos de colonialismo das concepções provenientes do Norte sobre as do Sul (mimetismo academicista, formalismo, "ideias fora do lugar", desconsideração das línguas e culturas locais);

- Crítica da formação de estudantes em administração (conteúdo, didática, visão de mundo propagada). Mesmo tipo de crítica aplicada à capacitação ou reciclagem de gerentes; 
- Crítica dos modelos gerenciais com base nos seus efeitos nocivos sobre as condições de vida e trabalho e sobre o meio ambiente. (Isso abrange questões de saúde, inclusive saúde mental, acidentes, insalubridade, insustentabilidade ambiental);

- Análise de experiências de resistência à imposição dos modelos gerenciais, tanto nas práticas produtivas quanto nas de ensino ou formação;

- Indagações sobre a possibilidade de modos de gestão alternativos, com ênfase na cooperação, democratização, humanização, solidariedade. Tais indagações levariam em conta experiências históricas e subsídios teóricos recentes.

A ideologia dominante que anima os processos de ensino, avaliação e publicação faz desaparecer da memória coletiva ideias e pensamentos que criticam o sistema. É então importante resgatar o pensamento crítico do passado, interpretar evoluções, remover esquecimentos. À luz de conhecimentos enraizados em diferentes tendências e épocas, inclusive as mais recentes, podemos refletir sobre a construção de novos quadros referencias para focar e interpretar os problemas das situações atuais.

De modo geral, o quadro referencial proposto articula as análises dos princípios teóricos e dos efeitos concretos na vida cotidiana. A crítica não se limita a um discurso diferente do dominante, ela se apoia em constatações de fatos, interpretações e discussão de valores. Argumentos genéricos, contrários à razão instrumental, aos interesses do capital, por exemplo, são insuficientes quando não contextualizados em estudos concretos.

Para um estudioso, ser crítico é uma atitude intelectual de distanciamento para com as interpretações dominantes. Essa postura não deve ser objeto de surenchère ou de ranqueamento. Sempre há relativismo no posicionamento crítico e, independentemente do contexto, parece inútil estabelecer qualquer ranking de criticidade segundo o qual, de modo definitivo, $X$ seria mais crítico que $Y$, sem respeitar as peculiaridades e circunstâncias de cada um.

\section{Interfaces e interdisciplinaridade}

Os Estudos Organizacionais podem ser apresentados como uma encruzilhada estabelecendo múltiplas interfaces entre fatos ou situações observáveis a partir de conhecimentos oriundos de várias disciplinas. Em geral, é nessas interfaces que surgem interrogações novas e conhecimentos novos.

Os conhecimentos preexistentes são agregáveis em torno do que é convencionalmente designado por Ciência da Gestão (Management 
Science), só que em perspectiva não atrelada à normatividade das práticas de gestão corrente. $\mathrm{O}$ pesquisador não se concentra na busca de soluções técnicas e utilitárias para resolver problemas imediatos.

Os enfoques adotados são enriquecidos por conceitos e métodos provenientes de várias áreas:

- Ciências sociais (sociologia, economia, história, antropologia, ciência política, etc.) e especializações como sociologia do trabalho, sociologia das organizações, sociologia econômica, sociologia dos movimentos sociais, sociologia da inovação...

- Psicologia: Psicologia social, psicologia organizacional, psicologia do trabalho, psicopatologia do trabalho, psicodinâmica do trabalho.

- Ciências da saúde: Medicina coletiva, psiquiatria, neurologia, enfermagem, gerontologia, etc.

- Ciências ambientais: ecologia política, impactos ambientais, trabalho, ambiente e saúde.

- Engenharia de produção, ergonomia, sistemas de informação, ciências da decisão.

- Filosofia, epistemologia, ética e filosofia moral.

- Educação, inclusive de adultos, teorias da aprendizagem.

- Comunicação: comunicação organizacional, teoria da informação, tecnologias de informação e comunicação, linguística, análises temáticas, de conteúdo e discurso, semiótica, semântica, pragmática da comunicação.

Os conhecimentos embasados nessas disciplinas, em termos de ensino e pesquisa, podem estar inter-relacionados para dar conta das interfaces entre as várias categorias de fatos, por exemplo, os procedimentos gerenciais impostos e a multiplicação dos casos de depressão e suicídio entre trabalhadores e executivos.

A interdisciplinaridade se situa em um nível superior ao da pluridisciplinaridade. Mais que uma multiplicação de olhares disciplinares, trata-se de promover abordagens transversais em torno de temas agregadores, por exemplo, sofrimento psíquico no trabalho, manifestações do autoritarismo, poder e cultura, assédio moral e violência, democratização das relações de trabalho, criação de novas formas de cooperação, etc. Consideramos que a interdisciplinaridade é uma condição importante mínima para viabilizar academicamente os Estudos Organizacionais.

Todavia, deve-se salientar que a proposta integrativa dos Estudos Organizacionais não significa que as disciplinas consideradas percam sua autonomia, a especificidade de suas problemáticas, suas próprias lógicas de desenvolvimento, seus fóruns de debate e critérios de avaliação. Especialistas de cada uma delas são apenas convidados a estabelecer parcerias de pesquisa, de ensino ou de publicação, em tempo parcial, em 
torno de temas organizacionais, sob a "bandeira" dos Estudos Organizacionais.

É possível ir mais longe com a transdisciplinaridade (NICOLESCU, 1999), muitas vezes confundida com a interdisciplinaridade, mas que é mais ambiciosa porque, além das relações entre disciplinas convencionais e das pontes que se podem erigir entre elas, existem outras propostas com ênfase na complexidade, transversalidade, multirrefencialidade, que não se limitam às disciplinas convencionais, mas estabelecem diálogos ou interlocuções com outros tipos de saberes, culturas, expressões estéticas e artísticas relacionados com os atores envolvidos nas situações. Esses atores são também considerados de modo diferenciado em função de características de gênero, etnia, religião.

A concepção transdisciplinar máxima pode ser aplicada aos Estudos Organizacionais, mas é claro que isso representa um desafio maior em termos de reconhecimento acadêmico e institucional. Os órgãos de fomento aceitam com restrição o que chamam de "áreas multidisciplinares" (simples adição de disciplinas convencionais), mas, em muitos casos, não enxergam a especificidade da interdisciplinaridade e, menos ainda, a ousadia da transdisciplinaridade que estabelece interlocuções entre vários tipos de saberes, o que nunca se enquadra em delimitações rígidas e regras burocráticas.

Uma atenção particular deve ser dada à relação que se estabelece entre uma ideia geral, de ordem teórica ou filosófica, de determinada tendência, com os dados empíricos, sejam eles qualitativos ou quantitativos, coletados em uma situação concreta e atual. Pode acontecer um tipo de "curto-circuito", isto é, uma conexão fortuita e não fundamentada, entre uma ideia geral produzida em um contexto filosófico, eventualmente de um período passado, e um dado específico extraído de uma observação no presente. É preciso tomar cuidado com a mágica das explicações obtidas por coincidências entre conhecimentos e informações de níveis de abstração diferentes e de contextos por vezes distantes. Também há riscos de abusar de argumentos de autoridade para, em conformidade com a teoria prévia, interpretar dados concretos que, em si mesmos, nem sempre são muito significativos.

\section{Uso de métodos}

Por serem diversificados teórica e conceitualmente, os Estudos Organizacionais também o são em matéria de metodologia. $\mathrm{O}$ uso de números e de técnicas quantitativas não é proibido, mas é evidente que os métodos de pesquisa qualitativa sejam privilegiados pela maioria dos autores.

Entre vários métodos utilizáveis, podemos distinguir:

1) Métodos de observação: Trata-se de descrever os fatos e situações concretas com a maior precisão possível e controlando vieses 
próprios à presença dos observadores. A observação pode ser realizada por meio de entrevistas de diversos tipos, individuais e coletivas, coleta de depoimentos, observação visual. Técnicas de etnografia também podem ser utilizadas. Por meio de observação, e mesmo com simples recursos de descrição, é possível mostrar uma imagem da realidade "crua e nua", contrapondo-a às representações fantasiosas, simuladas, edulcoradas ou enganosas, veiculadas pelos discursos dominantes. Nesse sentido, a observação pode contribuir para a crítica, desde que o pesquisador seja capaz de se livrar desses discursos.

2) Métodos de análise e interpretação. Devido à ênfase dada à pesquisa qualitativa, os principais métodos a serem utilizados são evidentemente de tipo interpretativo. Trata-se de analisar e interpretar a linguagem, os discursos teóricos (doutrinas organizacionais) e dos discursos práticos (falas de gerentes e outros entrevistados ou testemunhas). Para as interpretações, diversos recursos teórico-metodológicos podem ser considerados: hermenêutica, compreensão fenomenológica, historiografia, análise de narrativas, diálogos, análise crítica de argumentos, controvérsias e debates polêmicos, teoria dos atos de fala, semiótica, psicanálise, esquizoanálise, etc.

3) Métodos de design e planejamento. De modo propositivo, os Estudos Organizacionais podem oferecer sugestões e delineamentos para a criação (design) de novas formas organizativas, procedimentos de planejamento de atividades ou de instituições. O principal desafio é o de não se limitar a satisfazer exigências funcionais, mas de efetivar a aplicação de critérios orientados por valores democráticos ou emancipatórios.

4) Métodos de intervenção e participação. A possível adoção desse tipo de método é amplamente aceita em Estudos Organizacionais, como consta no Handbook of Organizacional Studies de Clegg et al. (1996) e, também, entre partidários da pesquisa qualitativa em geral. De acordo com Desroche, a participação nos processos de pesquisa pode existir com vários graus de intensidade e várias modalidades (THIOLLENT, 2006). Existem diferentes modalidades de pesquisa-ação e pesquisa participante, das quais não falaremos aqui. À participação correspondem regras de comportamento que, sozinhas, não garantem uma postura crítica. A respeito disso, não devemos entreter ilusões. A participação pode ser manipulada, desvirtuada em cooptação; os interesses subjacentes dos participantes podem distorcer seus discursos. A participação não é panaceia e nunca é perfeita; no entanto, não é por isso que se deva abandona-la. Recuar na participação pode significar voltar a uma postura mais tradicional, mais fechada, unilateral, própria ao cientificismo, impondo decisões sociopolíticas em nome da ciência. 
A participação é uma aposta para construir conhecimentos mais adequados para ações propositivas. Ela apresenta uma potencialidade crítica quando se contrapõe à exclusão ou à unilateralidade das relações entre os atores, à imposição de padrões elitistas, ou quando rompe o monopólio da interpretação.

Em síntese, do ponto de vista metodológico, os Estudos Organizacionais rompem em grande parte com o padrão positivista/moderno da investigação científica centrado em observação, objetividade, experimento, comprovação de hipóteses, neutralização da subjetividade do pesquisador, separação dos valores. Diferentemente, os Estudos Organizacionais se distanciam do predominante modelo de pesquisa das ciências exatas ou da natureza e possuem mais semelhanças com os estudos culturais, estudos literários e outros tipos de estudos humanísticos. Por sinal, existem na literatura, ricas analogias, metáforas, dramatizações que são significativas para a compreensão de situações de poder, sedução ou rejeição, encontráveis em organizações. O que importa são as interpretações dessas situações problemáticas e a busca de possíveis alternativas.

Outra questão metodológica recorrente em pesquisas, dissertações ou teses em Estudos Organizacionais diz respeito ao ponto de partida, cujo principal dilema é: ou partir de um quadro teórico prévio à pesquisa empírica, recuperando abstratas contribuições de diversos autores conhecidos, ou partir da observação de situações concretas ou da análise de experiências profissionais para construir a partir delas sistematizações, categorizações e, até, conceituações decorrentes, conforme a metodologia da chamada Grounded Theory (TAROZZI, 2011) ou de propostas construtivistas aparentadas que, eventualmente, se limitam à descrição.

Em nossa opção própria, endossada por antigas concepções da interação entre conhecimento e ação, sugere-se que o ponto de partido seja, de fato, a prática ou a experiência vivida, seguido por profundo esforço de reflexão teórica embasada em concepções de autores significativos, de competência específica e adequada à sutileza dos assuntos tratados, mas, sempre completado por uma volta à prática ou à experiência para enriquecê-la, ou redesenhá-la à luz da reflexão teórica e conceitual. Em síntese, estamos sugerindo uma variante do conhecido círculo ação-reflexão-ação, base de certa visão da dialética. Nesse círculo, o teor da reflexão não é simples referência ou citação de autores famosos. Pois, é comum encontrar na observação das práticas problemas concretos que não possuem respostas prontas e elaboradas nas teorias conhecidas e, então, precisam de um criativo esforço de argumentação, adaptação e interpretação.

\section{Conclusão}


Se o conhecimento é considerado como instrumento de poder, também podemos imaginar formas alternativas que seriam instrumento de contrapoder, oferecendo visões diferentes do mainstream e esclarecendo as ações de determinados atores ou movimentos.

[No passado, intelectuais críticos costumavam se manifestar publicamente. Sartre, Foucault e outros desciam na rua, iam à porta de fábricas ou de presídios para externar suas posições. Até Bourdieu usou o megafone numa assembleia de ferroviários em greve em 1995 contra o neoliberalismo.]

Imaginamos que, hoje, os estudiosos críticos das organizações tenham certamente algumas contribuições a dar aos trabalhadores sofrendo das consequências dos modelos de gestão autoritária (ventilados pelos manuais de management) e aos movimentos favoráveis a transformações sociais orientadas por valores democráticos.

Em suma, os Estudos Organizacionais não servem apenas para escrever artigos ou dissertações, têm papeis fundamentais a desempenhar na sociedade para, por exemplo:

- Criticar as concepções e as práticas organizativas dominantes e buscar propostas alternativas, embasadas em teorias e experiências práticas;

- Criticar os efeitos nocivos dos modelos e das práticas organizativas sobre sociedade, saúde, consumo, alimentação, cultura, meio ambiente;

- Avaliar projetos organizacionais, projetos de desenvolvimento, inovações tecnológicas e suas implicações organizacionais, com critérios que não se limitam à razão custo/benefício;

- Dar voz a atores que estão expressando a possibilidade de organizações diferentes.

Para uma maior circulação de informação e do conhecimento crítico não restrita aos pares e relevante para vários interlocutores sociais -, a busca de canais alternativos é necessária e, também, grandes esforços em matéria de ensino, promoção de eventos, divulgação e extensão universitária.

\section{Referências}

CLEGG, S.; R.; HARDY, C.; NORD, W. R. (org.). Handbook of organizational studies. London; Thousand Oaks; New Delhi: Sage, 1996.

DEJOURS, C. A banalização da injustiça social. 3.ed. Rio de Janeiro: Editora FGV, 2000. 
FARIA, J. H. de. (org.). Análise crítica das teorias e práticas organizacionais. São Paulo: Atlas, 2007.

NICOLESCU, B. O manifesto da transdisciplinaridade. São Paulo: TRIOM, 1999.

SANTOS, B. S. Para além do pensamento abissal: das linhas globais a uma ecologia de saberes. In: SANTOS, B.S.; MENESES, M.P. (orgs.). Epistemologias do Sul. São Paulo: Cortez, 2004. p. 31-83.

TAROZZI, M. O que é a grounded theory. Metodologia de pesquisa e de teoria fundamentada nos dados. Petrópolis: Vozes, 2011.

THIOLLENT, M. (org.). Pesquisa-ação e projeto cooperativo na perspectiva de Henri Desroche. São Carlos: EdUFSCar, 2006. 